and the oldest a gentleman in his sixties who worked as a caretaker at a school.

For those who wish to help with our cause, or who would even like to come and help next year, then please visit our website, as above. Our latest video for this camp can be found on YouTube by searching for Northern Cleft Foundation. Alternatively, just press 'like' on our Facebook page and follow our progress.

We would like to thank Dr George, Dr Venkat, all the cleft surgeons from the UK and all the 48 members of the NCF 2013 camp that worked relentlessly to provide a brighter future for those who thought it was beyond their reach. We of course must also extend our sincere thanks to all of the individuals who made generous donations to the Foundation.

J. Parmar, C. Sweet, by email

1. Parmar J. Hands-on training: working with a charity cleft team in Hyderabad. Br Dent $J$ 2007; 205: 291-293.

DOI: 10.1038/sj.bdj.387

\section{MRI SCAN HAZARD}

Sir, I came across a case when it was not possible to perform Magnetic Resonance Imaging due to previous routine dental treatment. One of our patients stated that during the MRI scan procedure 'the magnet nearly pulled his crowned teeth out'. The procedure was stopped due to the potential hazard. We tracked the patient's record down and discovered that a nonprecious alloy with high nickel content $(82 \%)$ was used in this case to make cast posts and crowns on 12 and 11. The interaction between dental restorations and MRI scans is an interesting topic which has not received much attention in the dental literature.

MRI units use strong magnetic fields and radio-frequency waves to create images. The magnetic field generated by the MRI scanner will attract objects containing ferromagnetic metals (iron, nickel, cobalt) with considerable force. While the MRI examination is a very useful non-invasive imaging technique with no known side effects, it may sometimes provide confusing results due to dental restorations.

Since the MRI scan was introduced in the 1970s, numerous studies have confirmed that precious alloys, amalgams and titanium implants generally cause minimal artefacts. Non-precious dental alloys have the potential of causing image deformation or image voids.

Dentists are not the only professionals implanting metal devices. Heart pacemakers and defibrillators, aneurysm clips, cochlear implants, insulin pumps, vascular stents, artificial joints etc are widely used in other branches of medicine. MRI technicians must conduct a careful evaluation of each patient and may alter the field strength to ensure the safety of the procedure. In some cases it is not possible to perform an MRI scan due to the risk of device dislodgement (eg some aneurysm clips) or malfunction (pacemakers). Extensive dental hardware with a high content of ferromagnetic metals, in some rare cases, can become a reason for a patient's ineligibility for an MRI procedure as well.

Every imaging modality can produce artefacts. Dental restorations can generate artefacts on both MRI and CT scans, with CT images being more affected by dental alloys due to the high attenuation of X-ray beam by metals. ${ }^{6}$ Severe image distortion or inability to perform the MRI scan due to dental restorations are rare problems, but cannot be completely eliminated. Precious alloys are superior not only in terms of biocompatibility, but also as they produce fewer artefacts on the MRI scan.

\section{Sinkiewicz, Peterborough}

1. Eggers G, Rieker M, Kress B, Fiebach J, Dickhaus $\mathrm{H}$, Hassfeld $\mathrm{S}$. Artefacts in magnetic resonance imaging caused by dental material. MAGMA 2005; 18: 103-111.

2. Shafiei F, Honda E, Takahashi H, Sasaki T. Artifacts from dental casting alloys in magnetic resonance imaging. J Dent Res 2003; 82: 602-606.

3. Costa A L, Appenzeller S, Yasuda C L, Pereira FR, Zanardi V A, Cendes F. Artifacts in brain magnetic resonance imaging due to metallic dental objects. Med Oral Patol Oral Cir Bucal 2009; 14: E278-E282.

4. Starcuk Z, Bartusek K, Hubalkova H, Bachorec T, Starcukova J, Krupa P. Evaluation of MRI artifacts caused by metallic dental implants and classification of the dental materials in use. Measurement SciRev 2006; 6: 24-27.

5. Lissac M, Coudert J L, Briguet A, Amiel M. Disturbances caused by dental materials in magnetic resonance imaging. Int Dent J 1992: 42: 229-233.

6. Klinke T, Daboul A, Maron J et al. Artifacts in magnetic resonance imaging and computed tomography caused by dental materials. PLoS One 2012; 7: e31766.

DOI: 10.1038/sj.bdj.2013.388

\section{JAW SURGERY ALTERNATIVES}

Sir, I recently treated a 14-and-a-halfyear-old boy with an overjet of over $12 \mathrm{~mm}$ with his lower incisors in contact with the palatal mucosa. He had previously been told by two consultants and a specialist orthodontist that he needed jaw surgery, although one consultant did suggest a 'compromise' result might be achieved with functional appliances. We said in advance that we saw no difficulty in correcting him with the 'postural' system that we use called orthotropics. This was achieved in two years although the postural training continued for a further two years, resulting in a correction of the overjet and substantial forward growth of the whole face.

Overjet correction of this severity has been achieved with functional appliances in the past but uniquely in this instance there was no increase in facial height. One of the greatest concerns in orthodontics is iatrogenic vertical growth which is endemic within all current treatment, reducing the dental arch length and damaging facial appearance, sometimes severely. As I had never before seen such a severe case corrected without an increase in vertical growth, I thought the profession should be aware that changing oral posture may have some merit and wrote a short case report for the $B D J$. Unfortunately, the referees strongly rejected this saying "the quality of the submission is less than I would expect from an undergraduate student' and 'in all likelihood this patient simply grew favourably'. This was clearly their opinion but I do not know of any evidence of conventionally treated cases having achieved an equivalent amount of favourable growth and one might ask 'why not'? The other referee dismissed the result as unremarkable saying 'all orthodontists who use functional appliances will have seen patients who have achieved a similar result', again a matter of personal opinion unsupported by any evidence and certainly the general evidence suggests that functional routinely increase vertical growth.

We should not forget that several hundred children and young adults are sent for surgery in the UK each year, many of them much less severe than this one, and I feel the profession should be allowed to consider alternative possibilities. Patients should have choice and perhaps the personal opinions of these two referees should not prevent this.

J. Mew, by email

DOI: 10.1038/sj.bdj.2013.389 